\title{
LEFT VENTRICULAR SURGICAL REMODELING 2.0
}

\author{
Antonio Calafiore ${ }^{1}$, Sotirios Prapas ${ }^{2}$, Kostas Katsavrias ${ }^{3}$, Massimo Di Marco ${ }^{3}$, Stefano \\ Guarracini $^{4}$, and Michele Di Mauro ${ }^{5}$ \\ ${ }^{1}$ John Paul II Foundation for Research and Treatment \\ ${ }^{2}$ Henry Dunant Hospital Center \\ ${ }^{3}$ Affiliation not available \\ ${ }^{4}$ Private Hospital Pierangeli Srl \\ ${ }^{5}$ Maastricht UMC+
}

October 5, 2020

\begin{abstract}
Left ventricular surgical remodeling (LVSR) has been, for long time, the procedure applied for large dyskinetic, or akinetic, areas as a consequence of a myocardial infarction, manly located in the left anterior descending area. Many surgical techniques were developed, aimed to a pure reduction of the volume of the left ventricular cavity or to add to volume reduction a more physiologic conical shape. The expansion of interventional procedures invaded most of the fields before treated only by cardiac surgeons. In this issue, Pillay describes an hybrid technique, involving both interventional cardiologists and cardiac surgeons, aimed to LV volume reduction after an anterior myocardial infarction. A series of internal (right ventricular septum) and external (anterior wall) anchors are implanted to approximate the LV free wall to the anterior septum, consequently excluding the scarred myocardium. Although some limitations of this study, the Authors have to be commended for having revitalized a procedure almost eliminated from the surgical scenario
\end{abstract}

\begin{abstract}
Left ventricular surgical remodeling (LVSR) has been, for long time, the procedure applied for large dyskinetic, or akinetic, areas as a consequence of a myocardial infarction, manly located in the left anterior descending area. Many surgical techniques were developed, aimed to a pure reduction of the volume of the left ventricular cavity or to add to volume reduction a more physiologic conical shape. The expansion of interventional procedures invaded most of the fields before treated only by cardiac surgeons. In this issue, Pillay describes an hybrid technique, involving both interventional cardiologists and cardiac surgeons, aimed to LV volume reduction after an anterior myocardial infarction. A series of internal (right ventricular septum) and external (anterior wall) anchors are implanted to approximate the LV free wall to the anterior septum, consequently excluding the scarred myocardium. Although some limitations of this study, the Authors have to be commended for having revitalized a procedure almost eliminated from the surgical scenario
\end{abstract}

Key-words: left ventricle; hybrid approach; volume reduction.

Left ventricular surgical remodeling (LVSR) has been, for long time, the procedure applied for large dyskinetic, or akinetic, areas as a consequence of a myocardial infarction, manly located in the left anterior descending area. Many surgical techniques were developed, aimed to a pure reduction of the volume of the left ventricular cavity ${ }^{1}$ or to add to volume reduction a more physiologic conical shape ${ }^{2-5}$. Long-term results were good, even if better outcome was reported with shape-based techniques ${ }^{6}$.

Many factors led to a progressive limitation of the surgical indications to LVSR. The most important was the widespread diffusion of primary angioplasty, that was able, through early revascularization, to limit the 
extension of necrosis and the dilatation of the necrotic area. Another important event was the publication of the STICH trial ${ }^{7}$, that casted shadows on the real benefit of adding LVSR to coronary artery bypass grafting $(\mathrm{CABG})$. Even if post-hoc studies demonstrated that, when the procedure was performed correctly the results were by far better than CABG alone ${ }^{8}$, this was not sufficient to reverse the trend and suddenly LVSR became an obsolete procedure.

On the other side the expansion of interventional procedures invaded most of the fields before treated only by cardiac surgeons, as myocardial revascularization, repair of mitral and tricuspid regurgitation, replacement of aortic and pulmonary valves, repair of prosthetic leaks, closure of atrial or ventricular septal defects, and so on. In the same time median sternotomy, and in general cardiac surgery, were considered the evil and the feeling that every solution was better than a cardiac surgical procedure diffused slowly but inexorably.

In this issue Pillay et $\mathrm{al}^{9}$ describe a modification of a hybrid technique by them previously used ${ }^{10}$, that allows interventional cardiologists and cardiac surgeons to work together to reduce the LV volume after an anterior myocardial infarction. A series of internal (right ventricular septum) and external (anterior wall) anchors are implanted to approximate the LV free wall to the anterior septum, consequently excluding the scarred myocardium. This technique was first applied by Wechsler et $\mathrm{al}^{11}$ using a median sternotomy. A pure surgical variant was used by Chiariello et $\mathrm{al}^{12}$, who performed the volume reduction via a left thoracotomy, without the aid of an interventional cardiologist. A more complex hybrid strategy was introduced to replace the median sternotomy. The internal anchor was deployed after being placed over a wire introduced through the internal jugular vein ${ }^{10}$ and the external anchor was positioned after a small left anterior thoracotomy.

In this study ${ }^{9}$ this technique was changed (and very likely improved) starting July 2018. The clinical results were very good: 47 cases reported (till January 2020), no in-hospital deaths, no complications, no late mortality, and clinical results reported an improvement of 1 NYHA class after a mean follow up of 9.8 months.

All these steps suggest that the involvement of the cardiologists was considered necessary to continue the experience with a different approach to LVSR. Reading the technique used by Wechsler et $\mathrm{al}^{11}$ it is evident that some problems can arise from the manipulation of a large heart without cardiopulmonary bypass. A left thoracotomy, as used in a case report by Chiariello et $\mathrm{al}^{12}$, provides a better approach and allows to deploy the intracardiac anchor through the anterior wall without the involvement of interventional cardiologists.

The Authors do not compare the clinical outcome of the different hybrid techniques by them used. Their most recent clinical study ${ }^{10}$ reports the results of the first version of hybrid technique $(n=35)$ which replaced the median sternotomy. Some mechanical complications, as tricuspid insufficiency increase and ventricular septal defect, were reported and very likely pushed to introduce some modifications. Whereas the latest version seems promising, nothing is said about what happened between March 2016 and July 2018. This is in line with the apparent reluctance of the Authors to report their full experience, limited to 12-month follow up and to more or less one third of the cases in their first study ${ }^{11}$, to 12 months (even if the experience, started in 2010 and reported in $2019^{10}$ could include a maximum follow up of at least 8 years) and in this report ${ }^{9}$, where the outcome is summarized in a few line. The enthusiasm for the good outcomes pushed the Authors to compare their series with the RESTORE registry. But comparing the early mortality of 1,198 patients with the early mortality of 47 patients is meaningless and does not add anything to the validity of the technique.

What reported by the Authors is brilliant and can have a future, mainly because of cardiologists' involvement. But the evidence of the validity of this hybrid strategy will go through many steps, first of all the demonstration a long term benefit and afterward a comparison with more standardized approaches. However, the Authors have to be commended for having revitalized a procedure almost eliminated from the surgical scenario.

\section{REFERENCES}

1. Dor V, Saab M, Coste P, Kornaszewska M, Montiglio F. Left ventricular aneurysm: a new surgical 
approach. Thorac Cardiovasc Surg 1989;37:11-9.

2. Guilmet D, Popoff G, Dubois C, et al. [A new surgical technic for the treatment of left ventricular aneurysm: the overcoat aneurysmoplasty. Preliminary results. 11 cases]. Arch Mal Coeur Vaiss 1984;77:9538.

3. Menicanti L, Castelvecchio S, Ranucci M, et al. Surgical therapy for ischemic heart failure: single-center experience with surgical anterior ventricular restoration. J Thorac Cardiovasc Surg 2007;134:433-41.

4. Calafiore AM, Gallina S, Di Mauro M, et al. Left ventricular aneurysmectomy: endoventricular circular patch plasty or septoexclusion. J Card Surg 2003;18:93-100.

5. Calafiore AM, Mauro MD, Di Giammarco G, et al. Septal reshaping for exclusion of anteroseptal dyskinetic or akinetic areas. Ann Thorac Surg 2004;77:2115-21.

6. Di Mauro M, Iaco AL, Bencivenga S, et al. Left ventricular surgical remodelling: is it a matter of shape or volume? Eur J Cardiothorac Surg 2015;47:473-9; discussion 9.

7. Jones RH, Velazquez EJ, Michler RE, et al. Coronary bypass surgery with or without surgical ventricular reconstruction. N Engl J Med 2009;360:1705-17.

8. Michler RE, Rouleau JL, Al-Khalidi HR, et al. Insights from the STICH trial: change in left ventricular size after coronary artery bypass grafting with and without surgical ventricular reconstruction. J Thorac Cardiovasc Surg 2013;146:1139-45 e6.

9. Pillay T, Neves P, Benetti F, van Bladel K, Wechsler A, Annest L. Minimal access left ventricvular reconstruction. J Card Surg 2020, in press.

10. Klein P, Anker SD, Wechsler A, et al. Less invasive ventricular reconstruction for ischaemic heart failure. Eur J Heart Fail 2019;21:1638-50.

11. Wechsler AS, Sadowski J, Kapelak B, et al. Durability of epicardial ventricular restoration without ventriculotomy. Eur J Cardiothorac Surg 2013;44:e189-92; discussion e92.

12. Chiariello GA, Nesta M, Bruno P, et al. Total Surgical Plication of Left Ventricular Aneurysm Using the BioVentrix Revivent Myocardial Anchoring System. Innovations (Phila) 2019;14:369-73. 